\title{
Erratum to: Miglitol administered before breakfast increased plasma active glucagon-like peptide-1 (GLP-1) levels after lunch in patients with type 2 diabetes treated with sitagliptin
}

\author{
Kazutaka Aoki • Hiroshi Kamiyama • \\ Kouichiro Yoshimura - Makoto Shibuya • \\ Kiyomi Masuda • Yasuo Terauchi
}

Published online: 1 November 2011

(C) Springer-Verlag 2011

\section{Erratum to: Acta Diabetol}

DOI 10.1007/s00592-011-0322-9

The original publication of this article contains some typographical errors in the legend of Fig. 5.

The correct version of the legend for Fig. 5 is given below:

Fig. 5 Plasma total GIP levels in miglitol-untreated and miglitol-treated groups. a Time profiles of the plasma total GIP levels. b AUCs of the plasma total GIP levels from after breakfast until $120 \mathrm{~min}$ after lunch for each group. c AUCs of the plasma total GIP levels after lunch for each group. The time data are presented as the mean $\pm \mathrm{SE}$. $* P<0.05$, ** $P<0.01$ and $* * * P<0.001$ versus miglitoluntreated group.

The online version of the original article can be found under doi:10.1007/s00592-011-0322-9.

K. Aoki · H. Kamiyama - M. Shibuya $\cdot$ K. Masuda .

Y. Terauchi $(\square)$

Department of Endocrinology and Metabolism,

Graduate School of Medicine, Yokohama City University,

3-9 Fukuura, Kanazawa-ku, Yokohama 236-0004, Japan

e-mail: terauchi@yokohama-cu.ac.jp

K. Aoki · H. Kamiyama - K. Yoshimura - M. Shibuya

Department of Endocrinology and Metabolism,

Yokosuka Kyousai Hospital, Yokosuka, Japan 